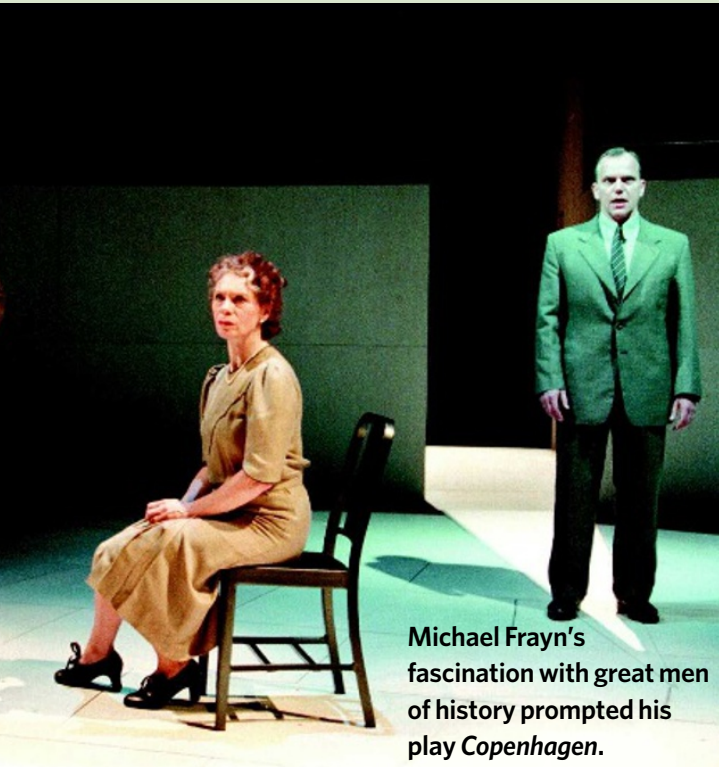

Frayn provides substantial 'postscripts' to each one, reprinted in the book, in which he lays out his source material, explains how he used it, and where and why he diverges from the historical record. For Copenhagen, he retraces the tremendous research he did into the physics and the physicists, from concepts of uncertainty and complementarity in quantum mechanics, to calculations of the critical mass of fissile material needed to make an atomic bomb, and the extent and nature of the German atomic weapons programme. His assessments of Bohr and Heisenberg are detailed and perceptive.

Frayn also discusses the 1945 detainment of Heisenberg and other German physicists at Farm Hall, a manor house outside Cambridge, UK, noting that 'the story of Farm Hall is another complete play in itself'. If only he would one day write it.

In a post-postscript, Frayn recounts how Copenhagen took on a life of its own and even changed the historical record, prompting first the revelation of draft letters from Bohr to Heisenberg about their 1941 meeting, and then the discovery of a letter Heisenberg wrote to his wife during that meeting, which took place, it turns out, on three separate days over a week. Although he wishes he had gained access to some of the documents earlier, especially Bohr's draft letters, he maintains that in the end, the play's integrity still stands.

One can see why he is drawn to Chekhov. The Russian, like Frayn, wrote novels and short stories before coming to playwriting late in life, for which he is arguably best known. Frayn's sympathy with Chekhov's 'struggles to understand and master the recalcitrant medium of the theatre' comes through in this fascinating collection: how difficult theatre is, by turns unpredictable, maddening, tedious, enthralling, crushing, exhilarating. In other words, just like science.

Kirsten E. Shepherd-Barr is a lecturer in modern drama at the University of Oxford, and a fellow and tutor in English at St Catherine's College, University of Oxford, UK. She is author of Science on Stage: From Doctor Faustus to Copenhagen.

e-mail: kirsten.shepherd-barr@ell.ox.ac.uk that can be incurred. She summarizes analytical techniques, including Fourier transform infrared and Raman spectroscopy, and supplies technical data that are useful to analytical chemists.

Shashoua includes dramatic case studies, such as the polyethylene head that was used to display a gas mask with vulcanized rubber strips. These had reacted chemically with the polyethylene so that the plastic head suffered irreversible and disfiguring degradation. This shows that sulphur-containing vulcanizing agents diffused from the gas mask into the polyethylene, and highlights the importance of using inert materials as display mounts for plastics.

Shashoua outlines available treatments, pitfalls associated with using solvents and the risks of cleaning and labelling plastics. She focuses on objects rather than media such as film, which is a specialization in itself. She highlights a need for better training for plastics curators, collectors and conservators, and outlines a strategy for surveying collections of plastics for degradation.

Global plastics production is rapidly increasing - around 230 million tonnes were produced in 2007. The compositions of emerging specialist plastics, such as composites, copolymers and blends, will make them even more difficult to identify and conserve and will challenge future collectors. With limited museum resources available, the future of plastics conservation will be subject to strict cost-benefit analysis. Saving Armstrong's space suit, for example, may warrant more expenditure than rescuing everyday, mass-produced plastic goods.

The book also touches on the conflicts between traditional conservation ethics and their application to new, short-lived materials, such as the biodegradable plastics being developed to offset mounting concerns about waste in landfills, landscapes and oceans. Biodegradable plastics provide increasing challenges to conservators as different types are being produced for an ever wider range of applications, from packaging to mobile phone casings.

The conservation of plastics is maturing as a discipline, but challenges lie ahead. Shashoua's guidelines in Conservation of Plastics do not supply all the answers, but they ensure the best chance of survival for current and future plastics collections into the twenty-second century. Susan Mossman is curator of Plasticity: 100 Years of Making Plastics at The Science Museum, London SW7 2DD, UK, and author of Fantastic Plastic.

\section{Robots refined}

The fifth ArtBots exhibition, running at Trinity College Dublin from 19-21 September, aims to challenge the traditional view of robots by showing that they can be art.

Just 15 of the 100 robots submitted have made this year's cut. Pete Redmond's RuBot II comes closest to what most expect a robot to be. With its humanoid torso, webcam eyes and pneumatic arms, the robot can solve a Rubik's cube in an average of 35 seconds.

Many of the works displayed subvert such stark efficiency. Allison Kudla's fragile-looking The Search For Luminosity frames six Oxalis plants with high-tech sensors and lights. When the plants raise their leaves looking for the expected Sun, a system of sensors turns on the exhibit's lights to provide sustenance. "The idea is about questioning and dismantling the hierarchy between the biological and the physical," says Kudla.

Other robots in the show look like they might date from before the Industrial Revolution. The most striking example is Ralf Baecker's Rechnender Raum ('Calculating Space'; pictured). "All the logic gates like and/or/not are formed by levers, strings and weights," explains Baecker. These units are connected by strings that communicate digital signals: a pulled string equals 1 , a loose string equals 0 . Through these strings, each cell in the framework receives and transmits instructions to neighbouring cells, resulting in a huge, primitive computer that sits and calculates with no regard to the viewer.

The show also features a panel discussion titled 'Are we living in a robotic cargo cult?'. Participants will discuss how ArtBot projects can confront the issue of whether current and future robots are "shaped by unrealistic and potentially de-humanizing science fiction fantasies". Their conclusions will feed in to an EU-funded project, Living with Robots and Interactive Companions.

Daniel Cressey is a reporter for Nature.

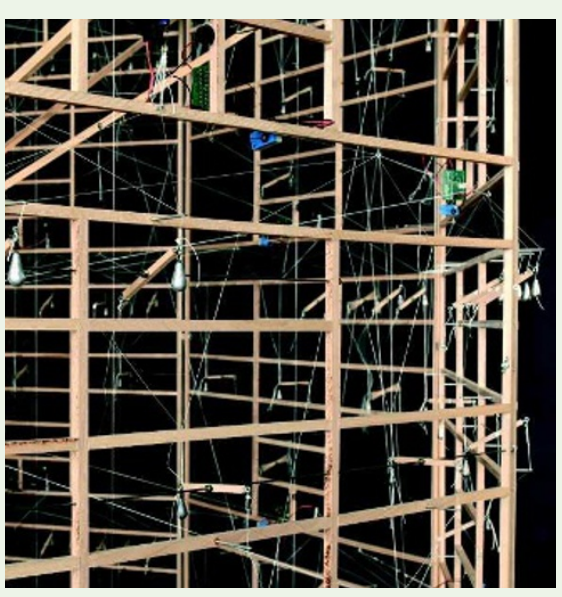

